\title{
Adopting universal lung function reference equations
}

\author{
Maureen P. Swanney ${ }^{1}$ and Martin R. Miller ${ }^{2}$
}

Affiliations: 'Respiratory Physiology Laboratory, Christchurch Hospital, Christchurch, New Zealand. ${ }^{2}$ Institute of Occupational and Environmental Medicine, University of Birmingham, Birmingham, UK.

Correspondence: M.R. Miller, Institute of Occupational and Environmental Medicine, University of Birmingham, Birmingham, B15 2TT, UK. E-mail: m.r.millerabham.ac.uk

○

@ERSpublications

Adopting the GLI 2012 lung function reference equations is an essential and urgent task for laboratories worldwide http://ow.ly/nIoyk

Since the dawn of spirometry and testing lung function $[1,2]$, clinicians have been aware that the values obtained from testing an individual's lung function can reflect the effects of lung diseases, and that this can be helpful with regard to all aspects of disease prevention and management. It was also recognised that the values obtained were also a reflection of the subject's sex, age and height; so to maximise the clinically relevant signal from the tests these aspects first needed to be taken into account. Studies were then undertaken to record lung function in subjects free from disease and free from the effects of tobacco smoke in order to have reference ranges of lung function.

Clinicians have had to decide which of the many available prediction equations to use for their patients, realising that the different equations might lead to different judgements about the results obtained, because predicted values might vary by as much as $1 \mathrm{~L}$ for forced expiratory volume in $1 \mathrm{~s}$ (FEV1) [3]. Guidance in this choice has been based on the reference population being appropriate for the patients and the equipment used for recording the lung function being equivalent. Other considerations include the age span of the reference population and the statistical approach used to derive the various predicted equations. Many European centres used the equations derived for the European Community for Steel and Coal (ECSC) [4]. However, it was still evident that different hospitals in a given locality might use very different prediction equations [5], meaning a patient's outcome might vary depending on which hospital they were tested at.

The Global Lung Initiative (GLI) was set up by the European Respiratory Society in 2010 with the remit to produce spirometry prediction equations that spanned all ages and could be used globally. These equations (GLI 2012) have been successfully produced [6] to the benefit of patients worldwide. Great credit should be given to the team that worked diligently to deliver these on time. Since the publication of the GLI 2012 prediction equations there have been validation studies undertaken in a wide range of ethnicities in British children [7] and in an Australasian population between 4-80 years [8], and these have shown that the GLI 2012 equations were appropriate.

In this issue of the European Respiratory Journal, QUANJER et al. [9] outline the possible effect that changing to the GLI 2012 equations might have in clinical practice. In this study, the authors compared hospital spirometry data in adults from Australia and Poland using the GLI 2012, ECSC and National Health and Nutrition Examination study (NHANES III) [10] prediction equations. The authors found that the GLI 2012 equations gave predictions similar to NHANES III values but were higher than ECSC. While there was little difference in identifying an obstructive spirometric pattern, the frequency of a restrictive pattern was higher when using GLI 2012 compared to ECSC and lower when using NHANES III.

Received: July 192013 | Accepted: July 222013

Conflict of interest: None declared.

Copyright @ERS 2013 
The GLI 2012 reference equations for spirometry have, by definition, international appeal for global standardisation for lung function. In 2005, the European Respiratory Society and the American Thoracic Society jointly published a series of lung function standardisation documents in the European Respiratory Journal, including spirometry [11] and its interpretation [12]. These updated the existing standards and have been widely embedded in pulmonary function laboratory practice, and have been adopted as usual practice by national respiratory societies around the world. However, they did not mandate the use of any particular reference equations, so there is now a sense of relief with the advent of the GLI 2012 equations because they embrace all ages and ethnicities in one coherent set of reference equations. This will simplify the confusion around which equations are appropriate to interpret spirometry. There is also the benefit of a seamless transition from childhood to adulthood using the same equations (GLI 2012), which removes the complication of switching to adult equations during longitudinal monitoring of patients with diseases such as cystic fibrosis [13]. There are many simultaneous factors such as height, growth and anatomical changes to consider when determining reference equations across adolescence [14]. In 2008, STANOJEVIC et al. [15] produced the first spirometry reference equations that provided smooth transition curves from childhood through adolescence during rapid growth and adulthood (age range 4-80 years). The GLI 2012 equations have been a further development of these and include a larger population, more ethnicities and a much older age range up to 95 years. This means we no longer need to extrapolate a prediction equation beyond the age range it was developed for, hoping that it will be appropriate for our elderly patients.

The GLI team used a sophisticated statistical approach to obtain the reference equations which included taking into account the range in variability with age. Younger and older subjects show higher variability than subjects in middle age. The GLI reference ranges use lower and upper limits of normal, and express a subject's results in terms of standardised residuals (z-scores). These state the number of population standard deviations the result is from predicted, which is the correct methodology for identifying if a result is unusual or unexpected [4, 12]. The use of well-defined lower limits of normal is more accurate [16] than the convenience of using a fixed cut-off value across all age groups. In addition, the widely used per cent predicted method is not based on any agreed scientific principle and leads to $20 \%$ misclassification of disease compared to the use of $\mathrm{z}$-scores [17].

The paper by QUANJER et al. [9] in this issue of the European Respiratory Journal demonstrates that while there will be minor changes in the interpretation of spirometry, as a result of changing reference values, the impact is trivial compared to the errors being made by using incorrect methodology such as per cent of predicted and fixed ratio for FEV1/forced vital capacity. So now the task before us is to get laboratories to change to the GLI 2012 equations. Lung function equipment manufacturers need to implement them in their equipment software as soon as possible, to allow access for all healthcare workers testing spirometry. The GLI working party have conducted a survey with the manufacturers of pulmonary function equipment, and the details about the implementation of the GLI 2012 equations into their software is included in a helpful table on their website [18]. In addition, spread sheets can be downloaded from the GLI website to help calculate results for patients, and there is a program, more suited to researchers, that calculates reference values for large datasets. However, these spread sheets are not so convenient for day-to-day use in the lung function laboratory.

Other issues for future consideration are the addition of GLI reference equations for static lung volumes and gas transfer testing in laboratories. Researchers will need to continue to check their results for any anomalies arising from use of the current and future GLI equations, such as sex, ethnic, age or height biases, so that the process can be continuously refined to the benefit of all our patients.

\section{References}

1 Thackrah CT. The Effect of Arts, Trades and Professions and of Civic States and Habits of Living on Health and Longevity. London, Longman, 1831.

2 Hutchinson J. On the capacity of the lungs, and on the respiratory function, with a view to establishing a precise and easy method of detecting disease by the spirometer. Medic-chirurgical transactions 1846; 29: 137-252.

3 Quanjer PH, Stanojevic S, Stocks J, et al. Spirometry reference values: situation in 2006. http://www.spirxpert.com/ gli_situation_in_2006.html Date last accessed: June 20, 2013.

4 Quanjer PH, Tammeling GJ, Cotes JE, et al. Standardized lung function testing. Lung Volumes and forced ventilatory flows. Eur Respir J 1993; 6: Suppl. 16, 5-40.

5 Dowson LJ, Mushtaq M, Watts T, et al. A re-audit of pulmonary function laboratories in the West Midlands. Respir Med 1998; 92: 1155-1162.

6 Quanjer PH, Stanojevic S, Cole TJ, et al. Multi-ethnic reference values for spirometry for the 3-95 years age range: the Global Lung Function 2012 equations. Eur Respir J 2012; 40: 1324-1343.

7 Lum S, Bonner R, Sonnappa S, et al. Validation of the GLI-2012 multi-ethnic spirometry reference equations in London school children. Thorax 2012; 67: A18.

8 Hall GL, Thompson BR, Stanojevic S, et al. The Global Lung Initiative 2012 reference equations reflect contemporary Australasian spirometry. Respirology 2012; 17: 1150-1151. 
9 Quanjer PH, Brazzale DJ, Boros PW, et al. Implications of adopting the Global Lungs Initiative 2012 all-age reference equations for spirometry. Eur Respir J 2013; 42: 1046-1054.

10 Hankinson JL, Odencrantz JR, Fedan KB. Spirometric reference values from a sample of general US population. Am J Respir Crit Care 1999; 159: 179-187.

11 Miller MR, Hankinson J, Brusasco V, et al. Standardisation of spirometry. Eur Respir J 2005; 26: 319-338.

12 Pellegrino R, Viegi G, Brusasco V, et al. Interpretive strategies for lung function tests. Eur Respir J 2005; 26: 948-968.

13 Rosenfeld M, Pepe MS, Longton G, et al. Effect of choice of reference equation on analysis of pulmonary function in cystic fibrosis patients. Pediatr Pulmonol 2001; 31: 227-237.

14 Lebowitz MD, Sherrill DL. The assessment and interpretation of spirometry during the transition from childhood to adulthood. Pediatr Pulmonol 1995; 19: 143-149.

15 Stanojevic S, Wade A, Stocks J, et al. Reference ranges for spirometry across all ages: a new approach. Am J Respir Crit Care Med 2008; 177: 253-260.

16 Swanney MP, Ruppel G, Enright PL, et al. Using the lower limit of normal for the FEV1/FVC ratio reduces the misclassification of airway obstruction. Thorax 2008; 63: 1046-1051.

17 Miller MR, Quanjer PH, Swanney MP, et al. Interpretating lung function data using $80 \%$ predicted and fixed thresholds misclassifies more than $20 \%$ of patients. Chest 2011; 139: 52-59.

18 Global Lung Function Initiative. Manufacturers. http://www.lungfunction.org/93-manufacturers.html Updated April 2013. Date last accessed: June 28, 2013. 